\title{
Improving transport aircraft fire safety through $\mathbf{R} \& D$
}

\author{
R. G. Hill \\ Fire Safety Team, US Federal Aviation Administration, USA
}

\begin{abstract}
This paper documents the US Federal Aviation Administration's Aircraft Fire Safety R\&D program. Areas featured include:

- Fuel tank flammability research in support of a new fuel tank flammability reduction rule. Both small and large scale testing, as well as computational modeling is discussed.

- Development of upgraded flammability test standards for materials in inaccessible areas of an aircraft, including ducting, electrical wiring and composite structure.

- Halon replacement efforts to develop test standards and test agents for use in engine nacelles, cargo compartments and handheld extinguishers.

- Developing standards for the safe transport of batteries and fuel cells in both the cargo compartment and in the passenger compartment.

- The use of magnesium in the aircraft interior. Initial testing will examine the use in seat frames. If it is determined that magnesium can safely be used in seats, other applications, such as ducting and galley carts, will be explored.

- $\quad$ Fire protection for freighter (all cargo) aircraft. This work is aimed at possible improvements in protection in the cargo compartments.

Additionally, this paper discusses international cooperation in the area of aircraft fire safety R\&D. FAA also conducts long-range research to develop the enabling technology for ultra-fire resistant materials, and to advance the scientific basis for understanding, measuring and predicting the burning behaviour of aircraft materials. This long-range R\&D is not addressed in this paper.
\end{abstract}

Keywords: fire safety, aircraft safety, Halon replacement, material safety, fire, research and development, FAA research. 


\section{Introduction}

The United States Federal Aviation Administration (FAA) and its predecessor agencies have been conducting Research \& Development (R\&D) in the area of aircraft fire safety for more than 60 years. The main emphasis of that R\&D has been and continues to be the improvement of safety standards in order to reduce the risk of fire related accidents and injuries/fatalities on aircraft. During the 1950 's and early 1960's the research focused on propulsion and fuel systems. With the introduction of jet aircraft that focus began the shift to other areas such as the flammability of interior materials and cargo fire suppression systems. As aircraft accidents became more impact-survivable, post crash fire survivability became a greater issue. Research in the 1970's and 1980's focused on reducing the risk of a post crash fire and improving material flammability standards inside the aircraft in order to improve survivability in the event of a post crash fire. The 1980 's also saw research in the area of cargo fire protection. Accidents in the 1990 's brought about major research efforts in the areas of cargo fire protection, fuel tank explosion protection and improved material flammability requirements of materials in inaccessible areas of the aircraft to lower the risk of in-flight fire.

\section{FAA aircraft fire safety $R \& D$ program}

The present FAA Aircraft Fire Safety R\&D Program has two major drivers, past accidents/incidents and changing technology. The program can be divided into two main topic areas, materials and systems, and each can be further sub divided into post crash or in-flight protection.

\subsection{Material flammability}

The material flammability program [1] evaluates the adequacy of the flammability standards and develops new standards as needed. The present program addresses both the in-flight and post crash scenarios and is comprised of the following projects:

\subsubsection{Inaccessible areas}

Driven by recommendations from the Transport Safety Board of Canada (TSB) based on their findings from the investigation into the crash of Swiss Air flight 111, the FAA has developed a new flammability standard for thermal acoustic insulation [2] and is committed to upgrading standards for other materials in inaccessible areas, as needed.

2.1.1.1 Ducting Initial large-scale testing of aircraft ducting [3] showed the inadequacy of the present standard. Subsequent research developed a new test method and standard that correlated with the large scale results. FAA is overseeing present research being conducted in laboratories around the world to assure the repeatability and reproducibility of that standard. 
2.1.1.2 Wiring Large-scale fire tests on wire bundles have also shown the current FAA requirement to be inadequate [4]. Present research is being conducted to develop a test method that will correlate to the large scale results.

2.1.1.3 Fuselage skin When composite material was proposed for use as a fuselage skin, the FAA recognized that the flammability properties of that usage category would have to be evaluated [5]. Since aluminium had been traditionally used for the fuselage skin material, there was no flammability requirement. The FAA believes this new material should be capable of safeguarding against the identical fire threat as previously imposed on thermal acoustic insulation and currently being developed for other materials in inaccessible areas.

\subsubsection{Use of magnesium}

Newly developed fire resistant magnesium alloys are now used in various modes of transportation, such as automobiles, busses and trains. Because of the potential weight saving from using magnesium as a replacement for aluminium in some applications within an aircraft fuselage, aircraft manufacturers have become very interested in its use. The FAA has begun a research program to determine if magnesium can be used safely within the aircraft. The first application area being evaluated is aircraft seat frames [6]. Preliminary laboratory testing has been positive. Full scale post crash fuel fire tests are scheduled for the spring of 2009. If it is determined that magnesium can be used safely in seat frames, then a small-scale certification test standard will be developed.

\subsubsection{Electrical components flammability}

New FAA advisory circular AC 21-16F identifies RTCA/DO-160F as an acceptable means of environmental qualifications for showing compliance with airworthiness requirements. However, the AC excludes Section 26, "Fire and Flammability" because it is not as stringent as FAA standards. The goal in this area is to draft a new Section 26 that will be acceptable to the FAA. An evaluation of currently used and accepted methods for qualifying electric enclosures and components to required flammability standards is underway. If necessary, new test methods, criteria, and/or procedures will be developed and incorporated in a revised document, RTCA/DO-160G [7].

\subsubsection{Present test method maintenance}

The FAA is constantly conducting research to maintain/improve currently required test methods to examine the reproducibility of flammability test results obtained by different laboratories. Round robin test programs are routinely conducted on the various test methods. Results are analyzed and corrective action taken where needed. Occasionally, a test apparatus, or parts there of, become obsolete and research is needed to develop replacements. An example of this is the oil burner used in the testing of seats, cargo liners and thermal acoustic insulation (for burn through resistance). The "Park" burner specified is no longer manufactured. Quality control of replacement parts for the existing burners has 
been shown to be a problem affecting reproducibility. Research is near completion to develop a suitable replacement burner [8].

\subsection{System fire protection}

This area of aircraft fire safety research can deal with fire protection systems, such as extinguishing systems, or fire protection of an aircraft system, such as fire resistant fluid for the hydraulic system [9]. The present systems R\&D program is aimed at in-flight accident prevention is as follows:

\subsubsection{Halon replacement}

Transport aircraft fire safety standards require fire suppression systems for all engine and auxiliary power unit compartments as well as most cargo compartments. Although the FAA does not mandate the type of agent to be used, Halon 1301 has become the only agent used for that application. Halon has been the agent of choice in aviation because of its weight to effectiveness ratio, low toxicity, ease of use, cleanliness (gaseous agent with no residue) and low cost. Additionally, hand held extinguishers are required on all aircraft. Because of its effectiveness in combating a wide range of potential in-flight cabin fires, Halon 1211 is required on all transport aircraft. Both of these agents, Halon 1301 and 1211, have a very high ozone depleting potential and have been banned from production internationally. Some countries have also banned their use, however, at present an exemption has been granted to aviation. In order to facilitate the conversion to alternate agents and ensure their equivalent effectiveness to halon, the FAA has developed what are called minimum performance standards (MPS) for each application [10]. Each MPS is comprised of the minimum requirements for replacement agents, for that application, including fire test methods for developing certification requirements for those agents.

2.2.1.1 Hand held extinguishers Present R\&D efforts focus on developing guidance material for the safe use of available replacement agents that pass the MPS [11] for use in all aircraft (the major concern is safe exposure limits in small aircraft/compartments). As these agents have a high global warming potential, R\&D is also underway to identify, evaluate and qualify to the MPS agents that would be more environmentally acceptable.

2.2.1.2 Engines The MPS for engines [12] was designed to evaluate gaseous replacement agents. Recent developments have lead to the need to modify the MPS to include powders and water mist as possible agents. This work is being coordinated through a task group of the International Aircraft System Fire Protection Working Group. After completion of that modification, the certification criteria for a proposed dry powder, an agent with zero ozone depletion and global warming potentials, will be developed.

2.2.1.3 Cargo At present there are no practical replacement agents or systems meeting the MPS available for use on transport aircraft [13]. As proposed agent/systems are identified, they will be tested for compliance with the MPS 
and certification criteria will be developed for the agents/systems shown to be compliant.

\subsubsection{Batteries and fuel cells}

New technology has lead to batteries that can store greater amounts of energy into smaller and lighter packages. This is good news for airline passengers since electronic devices such as cell phones and laptop computers are lighter and operate for longer times. Airframe manufacturers can reduce weight for traditional battery applications and use additional batteries where weight and space may previously have made it prohibitive. Research is being conducted to determine the fire risk of this new technology $[14,15]$. Methods for preventing a battery fire and for controlling it should it occur are being explored. Certification criteria for installation of these batteries on aircraft are being developed.

Another new technology in its infancy are fuel cells. Designed to pack more energy into a given package, last longer and recharge faster than batteries, these devises use electrochemical reactions involving hydrogen to produce electrical power. Research has recently been initiated to develop standards and requirement for their carriage, use, and installation on aircraft.

\subsubsection{Freighter fire protection}

Driven by National Transportation Safety Board (NTSB) recommendations emanating from their investigation into an in-flight fire on a UPS DC8 freighter (all cargo) aircraft, [16] the FAA is conducting research into the smoke detection and fire suppression requirements on freighter aircraft.

2.2.3.1 Smoke detection requirements Present smoke detection certification procedures require testing in empty compartments because it has been assumed to be the worst case condition. Testing is being conducted comparing empty and loaded compartment detection times for similar fire locations in order to evaluate the validity of that assumption [17].

2.2.3.2 Cost benefit analysis The FAA has commissioned RGW Cherry and Associates to perform a cost/benefit analysis for the conversion of class "E" compartments on freighter aircraft to class " $\mathrm{C}$ " compartments [18]. Although class "E" compartments require detection system they relay on depressurizing the compartment at an elevated altitude to suppress the fire, whereas, a class "C" compartment requires a suppression system and fire resistant liners.

2.2.3.3 Effectiveness of depressurization Although depressurization is the accepted means of fire control in a freighter aircraft, its effectiveness has never been studied in detail. In order to determine if more costly fire suppression requirements are warranted, the FAA is conducting research into the effectiveness of depressurization at altitude on the control of cargo fires [19].

\subsubsection{Fuel tank flammability}

Driven by the NTSB recommendation arising from their investigation into the fatal crash of TWA flight 800 , which was caused by a fuel tank explosion, the 
FAA has developed new safety requirements concerning the flammability of fuel tanks on transport aircraft.

2.3.4.1 Rule implementation support R\&D continues to support implementation of the fuel tank flammability rule. The Monte Carlo risk analysis model used to show compliance with the rule is being modified as problems are uncovered by users applying the model [20].

2.3.4.2 Aluminum verses composite fuel tanks The new fuel tank flammability rule requires that wing tanks on new designed aircraft employing non-conventional materials (e.g. composites) are no more flammable than that of traditionally designed aluminum wings. Research is ongoing to study the impact of using composites in wing construction on fuel tank flammability. Testing to date has shown that composite wings can be more flammable on the ground and remain flammable longer once airborne than aluminum tanks. Research will study the effects of thickness, type, coatings and colour of composites on wing tank flammability [21].

\section{International harmonization}

The FAA coordinates its Fire Safety R\&D through three Working Groups. The Cabin Safety Research Technical Group (CSRTG) [22] is comprised of members from each participating aviation authority, with representation from both the research and regulatory elements of each organization (i.e., 'performing' and 'customer' groups). The CSRTG meets regularly (approximately 3-5 times a year) and as needed to ensure the achievement of the Group's objectives and the proper conduct and progress of the research efforts.

Other authorities-related representatives (such as members of external research organizations or other government agencies) are invited to participate in some of the CSRTG's work, as and when needed to address specific issues/activities. The CSRTG is responsible for the identification, prioritization, planning, coordination and general direction (but not day to day management) of the various projects, and for regular briefings to management on the progress and findings of the various research efforts. In addition to the above, input relative to research needs and priorities is, as appropriate, sought and received from pertinent authorities-associated working groups and advisory committees [such as the Aviation Rulemaking Advisory Committee (ARAC), the Research, Engineering and Development Advisory Committee (REDAC), the JAA Cabin Safety Steering Group (CSSG), and the FAA/JAA/TCA International Cabin Safety Team (iCST)], as well as from recognized public- and industry-associated working groups.

The second Group is the International Aircraft Materials Fire Test Working Group (IAMFTWG) [1]. This Group is Chaired and administered by the FAA. Issues and concerns in the area of aircraft materials fire safety testing are discussed with emphasis on the current test methods and R\&D activities.

For example, the status of round robin tests involving the OSU/NBS test methods, Bunsen burner test method, and oil burner tests for seats and cargo 
liners are presented and discussed. Working group members are encouraged to open a discussion on any new topic related to aircraft materials fire safety. The Group meets three times per year, one meeting is held in Atlantic City, New Jersey, near the FAA Technical Center, one meeting at another location in North America, and one meeting outside North America.

The third Working Group is the International Aircraft Systems Fire Protection Working Group (IASFPWG) [9], which was originally established as the International Halon Replacement Working Group in October 1993. The original group developed minimum performance standards and test methodologies for non-halon aircraft fire suppression agents/systems in cargo compartments, engine nacelles, hand held extinguishers, and lavatory trash receptacles. The group's activities have been expanded to include all system fire protection R\&D for aircraft.

Current meeting topics include testing results for halon replacement agents in accordance with the minimum performance standards for aircraft handheld extinguishers, cargo compartment fire suppression systems, and engine nacelles; fuel tank explosion protection (including fuel flammability, nitrogen inerting, and other methods of explosion protection); fire detection and extinguishment in hidden areas of the aircraft, and lithium battery fire hazards and fire extinguishment. The group meets twice per year, one meeting is held in Atlantic City, New Jersey, area and one meeting is held at a host organization at another location.

Both the IAMFTWG and the IASFPWG are open to anyone in the international community in industry, government and academia with an interest in aircraft fire safety.

\section{The future for fire safety $R \& D$}

As stated previously, the major drivers for fire safety R\&D are accidents/incidents and changing technology. Changing technology is more predictable than future accidents/incidents, however, new technology can also bring unforeseen problems and surprises. Therefore, the prediction of future fire safety $R \& D$ is an educated guess and is subject to change.

Halon replacement will continue to be a major issue in aviation needing additional R\&D. Emphasis will be placed on agents that are both of a non-ozone depleting and low global warming nature. Research will cover all three of the main usage areas in an aircraft (hand held extinguishers, cargo compartments, and engine nacelles). New agents will be evaluated and certification criteria developed.

A major manufacturing trend to changes from traditional metallic construction (use of aluminum) to combustible composites will lead to a reevaluation of the present flammability requirements. Flammability standards and fire test methods will have to be developed, where none presently exist because the materials traditionally used were non-combustible, if changing technology now allows for the use of lower combustibility materials. Additionally, if magnesium becomes acceptable in seat frames, other usage areas will certainly 
be proposed. Research will be needed to determine safe applications and develop adequate flammability test standards.

A major area that should be addressed in the future is the carriage of oxygen onboard aircraft. Both gaseous and solid oxygen generator have been a source of fires on aircraft. New technology may make it feasible to generate oxygen from air in-flight, as needed, thus eliminating the need to store it. R\&D should be undertaken to apply this new technology in solving this safety issue.

Numerous other areas may need addressing in the future such as the effect of alternative fuels (e.g., biofuels) on aircraft fire issues, the flammability of hydraulic and cooling fluids, and post crash fire penetration of windows. As in the past, there will always be a need for R\&D to solve problems with existing requirements and test methods as they arise.

\section{References}

[1] U.S. Federal Aviation Administration. Fire Safety Team. www.fire.tc.faa.gov/materials.asp

[2] Marker, T., Development of Improved Flammability Criteria for Aircraft Thermal Acoustic Insulation, DOT/FAA/AR-99/44, 2000

[3] Reinhardt, J.W., Development of an Improved Test Method for Aircraft Ducting Materials, DOT/FAA/AR-08/4, 2008

[4] Cahill, P., An Evaluation of the Flammability of Aircraft Wiring, DOT/FAA/AR-TN04/32, 2004

[5] Federal Aviation Administration, Special Conditions: Boeing Model 787-8 Airplane; Composite Fuselage In-Flight Fire/Flammability Resistance, Federal Register Vol. 72, No.80, April 26,2007

[6] Marker, T., Update on Flammability Testing of Magnesium Alloy Components, http://www.fire.tc.faa.gov/pdf/materials/March09Meeting /marker-0309-Magnesium.pdf, 2009

[7] Cahill, P., RTCA Update, http://www.fire.tc.faa.gov/pdf/materials/ March09Meeting/Cahill-0309-RTCA_Update.pdf, 2009

[8] Ochs, R.I., Analysis and Design of the Federal Aviation Administration Fire Test Burner, http://www.fire.tc.faa.gov/pdf/materials/ March09 Meeting/ochs-0309-PIV.pdf, 2009

[9] U.S. Federal Aviation Administration. Fire Safety Team. http://www.fire.tc.faa.gov/systems.asp, 2009

[10] Federal Aviation Administration, Halon Replacement Performance Testing (Notice No. 93-1), Federal Register Vol. 58, No.115, June 17,1993

[11] Webster, H., Development of a Minimum Performance Standard for HandHeld Fire Extinguishers as a Replacement for Halon 1211 on Civilian Transport Category Aircraft, DOT/FAA/AR-01/37, 2002

[12] U.S. Federal Aviation Administration. Fire Safety Team, http://www.fire.tc.faa.gov/systems/engine/engine.stm

[13] U.S. Federal Aviation Administration. Fire Safety Team. http://www.fire.tc.faa.gov/systems/cargo/cargo.stm 
[14] Webster, H., Flammability Assessment of Bulk-Packed, Rechargeable Lithium-Ion Cells in Transport Aircraft, DOT/FAA/AR-06/39, 2006

[15] Webster, H., Flammability Assessment of Bulk-Packed, Non-rechargeable Lithium Primary Batteries in Transport Aircraft, DOT/FAA/AR-04/26, 2004

[16] National Transportation Safety Board, Recommendations Letter, http://www.ntsb.gov/Recs/letters/2007/A07 97_103.pdf, 2007

[17] Blake, D., Class E Cargo Compartment Smoke Detection and Active ULD Testing, http://www.fire.tc.faa.gov/pdf/systems/Nov08Meeting/Blake-1108 -ClassESmokeDetection.pdf, 2008

[18] Cherry, R.G.W. and Associates, A Cost Benefit Analysis for the Installation of Fire Suppression Systems in Cargo Compartments of Cargo Aircraft, DOT/FAA/AR-09/17, 2009

[19] Hill, R., Cargo Fire Suppression by Depressurization Tests, http://www.fire.tc.faa.gov/pdf/systems/Nov08Meeting/Hill-1108SuppressionViaDepressurization.pdf, 2008

[20] Federal Aviation Administration, Reduction of Fuel Tank Flammability in Transport Category Airplanes, Federal Register/Vol. 73, No. 140/Monday, July 21, 2008

[21] Summer, S., Cavage, W., Composite and Aluminium Wing Tank Flammability Comparison Testing, http://www.fire.tc.faa.gov/pdf/ systems/Nov08Meeting/summer-1108-CompositeWingFlammability.pdf, 2008

[22] U.S. Federal Aviation Administration. Fire Safety Team. http://www.fire.tc.faa.gov/cabin.stm, 2009 